\title{
PENGEMBANGAN PRODUK "BERAS ANALOG” UNTUK MENINGKATKAN PENERIMAAN PASAR
}

\section{DEVELOPING “ANALOG RICE” PRODUCT TO INCREASE MARKET ACCEPTANCE}

\author{
Dian Novitasari1 ${ }^{1}$, Aji Hermawan²), dan Titi Candra Sunarti ${ }^{2}$ \\ ${ }^{1)}$ Program Studi Teknologi Industri Pertanian, Fakultas Teknologi Pertanian, Institut Pertanian Bogor \\ Kampus IPB Darmaga, Bogor 16680, Indonesia \\ E-mail: DianNovitasari06@yahoo.co.id \\ ${ }^{2)}$ Departemen Teknologi Industri Pertanian, Fakultas Teknologi Pertanian, Institut Pertanian Bogor, Indonesia
}

Makalah: Diterima 1 Maret 2017; Diperbaiki 13 Juni 2017; Disetujui 20 Juni 2017

\begin{abstract}
The "analog rice" (artificial rice) is a new product that has difficulties to enter the Indonesian market. The aim of this research was to analyze the development of the analog rice to enter the market. The steps were divided into three stages, i.e. to analyze the attributes considered in purchasing rice grain, to analyze the level of satisfaction and dissatisfaction of the analog rice attributes, and to analyze the development priority of the analog rice attributes. The data were collected by interview and survey questionnaire. The data were processed using descriptive analysis, quantitative analysis, category frequency distribution, Kano method, and analysis of quality improvement index. This research resulted in that there were 17 attributes to be considered by respondents in purchasing rice grain. Fragrance was the analog rice attribute that had highest satisfaction effect, cleanliness was the analog rice attribute that had highest dissatisfaction effect, and the large size of grain was the analog rice attribute that had lowest satisfaction and also lowest dissatisfaction. The development priority of the analog rice attributes included good taste, economical price, fragrance, sticky texture, and product consistency after cooking.
\end{abstract}

Keywords: artificial rice, food diversification, Kano method, product development

\section{ABSTRAK}

"Beras analog" (beras buatan) merupakan produk baru yang memiliki hambatan dalam menembus pasar Indonesia. Tujuan penelitian ini adalah menganalisis pengembangan produk beras analog dalam menembus pasar. Penelitian ini dibagi ke dalam tiga tahapan, yaitu menganalisis atribut yang menjadi pertimbangan dalam membeli beras, menganalisis tingkat kepuasan dan ketidakpuasan dari atribut yang dimiliki oleh beras analog, dan menganalisis prioritas pengembangan dari atribut beras analog. Pengumpulan data dilakukan melalui wawancara dan survey kuesioner. Data diproses dengan analisis deskriptif, analisis kuantitatif, distribusi frekuensi kategori, metode Kano, dan analisis quality improvement index. Penelitian ini menghasilkan 17 atribut yang menjadi pertimbangan responden dalam melakukan pembelian beras. Atribut beras analog yang berpengaruh tinggi terhadap kepuasan adalah aroma, yang berpengaruh tinggi terhadap ketidakpuasan adalah kebersihan, dan berpengaruh rendah pada kepuasan dan ketidakpuasan adalah ukuran butiran. Prioritas atribut beras analog untuk dilakukan pengembangan meliputi rasa yang enak, harga yang ekonomis, aroma yang wangi, tekstur yang pulen, dan tahan lama setelah dimasak.

Kata kunci: beras buatan, metode Kano, penganekaragaman pangan, pengembangan produk

\section{PENDAHULUAN}

Saat ini hampir $90 \%$ penduduk Indonesia mengkonsumsi beras sebagai sumber pangan pokok (Kementan, 2012) dengan jumlah konsumsi perkapita pada tahun 2014 sebesar 84,64 kg/tahun (Kementan, 2015). Seiring dengan bertambahnya jumlah penduduk setiap tahunnya dikhawatirkan produksi beras tidak dapat mencukupi kebutuhan penduduk (Caesarina dan Estiasih, 2016). Upaya yang dapat dilakukan untuk mengatasi permasalahan tersebut adalah dengan melakukan penganekaragaman pangan, yaitu dengan memanfaatkan sumber karbohidrat lokal non beras menjadi beras "analog" agar tidak mengubah kebiasaan konsumsi masyarakat Indonesia (Budijanto, 2014).

"Beras analog" merupakan beras buatan yang terbuat dari sumber pangan karbohidrat lokal non padi (Budijanto dan Muaris, 2013). Keberadaan "beras analog" di Indonesia masih baru dan belum dikenal oleh masyarakat luas. Hal ini dikarenakan "beras analog" masih diproduksi dan dipasarkan dalam skala terbatas. Saat ini "beras analog" yang diproduksi oleh PT. Fits Mandiri, baru dipasarkan pada gerai Serambi Botani. Penjualan "beras analog" pada gerai Serambi Botani sudah dimulai sejak November 2012. Sampai saat ini "beras analog" masih mengalami hambatan dalam menembus pasar, hal tersebut dapat dilihat dari data penjualan "beras analog" pada gerai Serambi Botani pada Gambar 1 . 
Gambar 1 menunjukkan data penjualan "beras analog" pada tahun 2016 dari bulan Januari hingga Juli untuk "beras analog" ukuran 800 g secara berturut-turut sebanyak: 166 buah, 209 buah, 145 buah, 257 buah, 199 buah, 209 buah, dan 119 buah, sedangkan untuk 'beras analog' ukuran 250 g secara berturut-turut sebanyak: 108 buah, 147 buah, 80 buah, 116 buah, 93 buah, 93 buah, dan 68 buah.

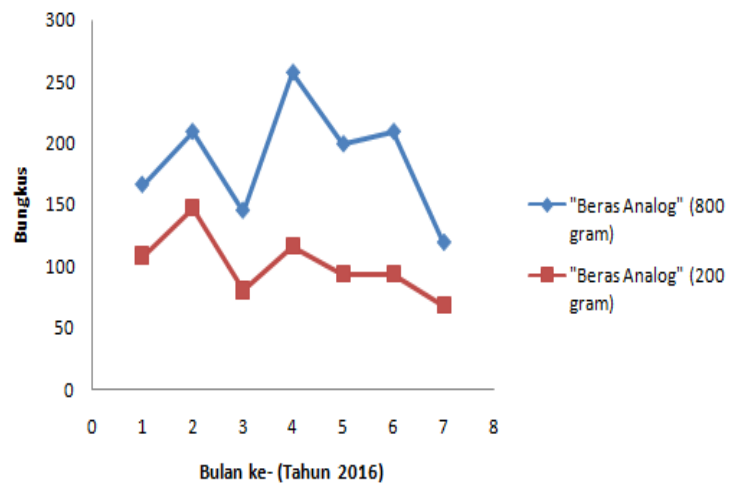

Sumber: Serambi Botani

Gambar 1. Data penjualan "beras analog” pada gerai Serambi Botani

Data tersebut menunjukkan bahwa terjadi hambatan dalam melakukan pengembangan produk "beras analog" yang dapat dilihat dari penurunan volume penjualan "beras analog" yang terjadi pada Maret, Mei, dan Juli. Hal tersebut dikarenakan "beras analog" merupakan produk baru, sebagai produk baru banyak upaya yang harus dilakukan oleh PT. Fits Mandiri selaku produsen agar dapat diterima oleh pasar sehingga dapat meningkatkan volume penjualan "beras analog". Menurut Rusmadi (2016), salah satu upaya yang dapat dilakukan untuk mengatasi permasalahan tersebut adalah melakukan perencanaan produk (pengembangan produk) sesuai dengan kebutuhan pasar (preferensi konsumen). Menurut Yuktyanta (1998), pengembangan produk baru merupakan alat strategis bagi perusahaan agar dapat bertahan serta memenangkan kompetisi pasar yang ketat dengan cara menghasilkan suatu produk yang memiliki keunggulan-keunggulan kompetitif. Pengembangan produk perlu dilakukan agar dapat merancang strategi pemasaran yang efektif dikarenakan produk merupakan titik sentral dari kegiatan pemasaran. Pemasaran merupakan salah satu dari kegiatan pokok yang harus dilakukan oleh perusahaan untuk menambah volume penjualan.

Saat ini PT. Fits Mandiri belum mengetahui apakah atribut produk "beras analog" sudah sesuai dengan harapan konsumen, sehingga sampai saat ini belum terdapat kajian yang menggambarkan apakah atribut yang dimiliki oleh "beras analog" sudah sesuai dengan penerimaan pasar. Berdasarkan permasalahan tersebut, maka perlu dilakukan suatu kajian untuk mengetahui penerimaan pasar produk "beras analog" dengan mempertimbangkan atributatribut yang menjadi pertimbangan dalam melakukan pembelian beras, dikarenakan tingginya ketergantungan terhadap beras. Kajian ini dilakukan untuk mengetahui penerimaan "beras analog" oleh pasar, sehingga dapat mengetahui atribut mana yang sudah sesuai dengan penerimaan pasar dan atribut mana yang belum sesuai, agar dapat dilakukan pengembangan atribut produk "beras analog" yang belum sesuai dengan permintaan pasar. Hal tersebut dikarenakan menurut Kotler dan Keller (2009) serta Rini (2013), pengembangan produk merupakan faktor penting untuk mengimplementasikan strategi produk yang sesuai dengan penerimaan pasar dalam menentukan keberhasilan perusahaan, membentuk masa depan perusahaan, dan meningkatkan penjualan.

Berdasarkan uraian di atas, maka tujuan utama dari penelitian ini adalah menganalisis produk "beras analog" untuk meningkatkan penerimaan pasar. Sementara tujuan khusus dari penelitian ini adalah 1) menganalisis atribut yang menjadi pertimbangan dalam membeli beras; 2) menganalisis tingkat kepuasan dan ketidakpuasan atribut beras "analog"; dan 3) menganalisis prioritas pengembangan atribut beras "analog".

\section{METODE PENELITIAN}

\section{Waktu dan Tempat Penelitian}

Penelitian dilaksanakan di gerai Serambi Botani yang berada di Jakarta, Bogor, Tangerang, dan Bekasi, serta beberapa wilayah di Jabodetabek. Pemilihan lokasi penelitian dilakukan secara sengaja (purposive) yaitu dengan mempertimbangkan bahwa Serambi Botani merupakan tempat pemasaran produk "beras analog", dan Jabodetabek dikarenakan mayoritas konsumen "beras analog" berada di wilayah tersebut. Pengambilan data penelitian telah dilaksanakan dari September 2016 hingga April 2017.

\section{Jenis dan Sumber Data}

Jenis data yang digunakan dalam penelitian ini berupa data primer yang bersifat kualitatif dan kuantitatif. Data penelitian diperoleh dari hasil wawancara dan pengisian daftar pertanyaan (kuisioner) dari responden penelitian.

\section{Tahapan Penelitian}

Penelitian ini diawali dengan melakukan analisis kepentingan atribut yang menjadi pertimbangan responden dalam membeli beras. Penelitian dilanjutkan dengan melakukan analisis tingkat kepuasan dan ketidakpuasan responden terhadap atribut yang dimiliki oleh "beras analog". Penelitian kemudian dilanjutkan dengan melakukan analisis priotitas pengembangan atribut "beras analog". Untuk lebih jelasnya dapat dilihat pada Gambar 2. 


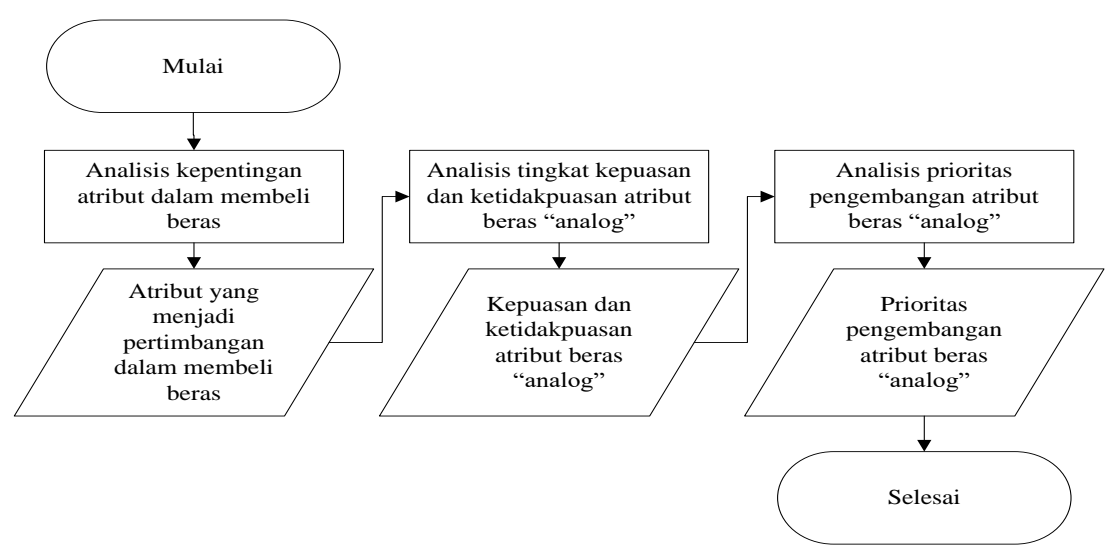

Gambar 2. Tahapan penelitian

\section{Analisis Atribut yang Menjadi Pertimbangan Responden dalam Membeli Beras}

Tahapan ini bertujuan untuk mengetahui voice of customer yang menjadi pertimbangan dalam melakukan pembelian beras. Responden penelitian dipilih dengan menggunakan metode nonprobability sampling technique yaitu dengan teknik purposive sampling dan snowball sampling. Prinsip dasar jumlah partisipan yang digunakan sebagai responden dalam penelitian ini adalah saturasi data, yaitu pada suatu titik kejenuhan dimana tidak ada data baru yang didapatkan dari partisipan, sehingga pengumpulan data dihentikan setelah saturasi tercapai (Fusch dan Ness, 2015).

Kriteria yang dipilih untuk dijadikan responden penelitian meliputi (1) konsumen "beras analog" yang dipasarkan di gerai Serambi Botani dan (2) segmentasi pasar "beras analog" yang mengacu hasil penelitian Rizki et al. (2013), yaitu dengan kriteria perempuan berusia $\geq 31$ tahun, status menikah, tingkat pendidikan minimal S1, dan tingkat pendapatan perbulan $\geq \mathrm{Rp}$ 4.500.000 Data dianalisis secara deskriptif, kuantitatif, dan distribusi frekuensi kategori (Sulistiyowati dan Astuti, 2016), sehingga mendapatkan informasi mengenai atribut yang menjadi pertimbangan dalam membeli beras. Output yang didapatkan digunakan sebagai input dalam pembuatan kuesioner pada tahap berikutnya.

Cara pencarian responden yang merupakan konsumen "beras analog" diperoleh dari gerai Serambi Botani dengan jumlah responden sebanyak 7 orang, sedangkan untuk responden yang merupakan segmentasi pasar "beras analog" didapatkan dengan melakukan pembuatan website. Pembuatan website tersebut bertujuan untuk menjaring responden yang memiliki kriteria yang sesuai dengan segmentasi pasar "beras analog" dan bersedia untuk dijadikan responden dalam penelitian, dari pengisian data website tersebut didapatkan hasil pengisian yang bersedia untuk menjadi responden sebanyak 21 orang, namun hanya terdapat 11 orang yang sesuai dengan kriteria untuk dijadikan responden penelitian.

Data pengisian website tersebut dari 11 orang yang memenuhi kriteria digunakan sebagai patokan untuk mencari responden lain yang memiliki kriteria serupa dengan metode snowball sampling. Pengumpulan data dilakukan dengan menggunakan metode survei melalui wawancara terbuka dengan sistem saturasi data. Saturasi data yang dihasilkan pada penelitian ini adalah dengan jumlah responden keseluruhan sebanyak 30 responden. Data yang dihasilkan dari wawancara kemudian dianalisis. Data dianalisis secara deskriptif, kuantitatif, dan distribusi frekuensi kategori (Sulistiyowati dan Astuti, 2016), sehingga mendapatkan informasi mengenai atribut yang menjadi pertimbangan dalam membeli beras (voice of customer).

\section{Analisis Tingkat Kepuasan dan Ketidakpuasan dari Atribut Beras "Analog"}

Beras "analog" yang digunakan dalam penelitian ini merupakan beras "analog" dengan bahan baku tepung jagung dan sagu yang diproduksi oleh PT. Fits Mandiri dan dipasarkan pada gerai Serambi Botani. Pengumpulan data dilakukan menggunakan metode survei dengan kuesioner dalam bentuk pertanyaan tertutup. Survei dilakukan kepada responden yang sama dengan tahap sebelumnya. Kuesioner yang diberikan kepada responden adalah kuesioner Kano yang berupa pertanyaan functional dan disfunctional (Berger, 1993; Sauerwein, 1996; Matzler dan Hinterhuber, 1998). Sebelum dilakukan pengisian kuesioner, terlebih dahulu responden dijelaskan mengenai "beras analog". Selanjutnya responden diberikan sampel produk beras "analog" ukuran $250 \mathrm{~g}$ dan kuesioner. Data yang didapatkan dari pengisian kuesioner dianalisis dengan metode Kano (Berger, 1993; Sauerwein, 1996; Matzler dan Hinterhuber, 1998).

Langkah awal yang dilakukan dalam analisis adalah menterjemahkan jawaban-jawaban dari kuesioner yang telah diisi oleh responden ke dalam tabel evaluasi Kano (Berger, 1993; Sauerwein, 1996; Matzler dan Hinterhuber, 1998), seperti yang tertera pada Tabel 1 . 
Tabel 1. Evaluasi Kano

\begin{tabular}{llccccc}
\hline \multirow{2}{*}{ Customer Requirements } & \multicolumn{5}{c}{ Disfunctional } \\
\cline { 2 - 6 } & Suka & Suka & Harus & Netral & Boleh & Tidak suka \\
\hline \multirow{3}{*}{ Functional } & Q & A & A & A & O \\
& Harus & R & I & I & I & M \\
& Netral & R & I & I & I & M \\
& Boleh & R & I & I & I & M \\
& Tidak Suka & R & R & R & R & Q
\end{tabular}

Keterangan: $\mathrm{A}=$ Attractive (menarik); $\mathrm{M}=$ Must-be (harus ada); $\mathrm{O}=$ One-dimensional ( - $a t u$ dimensi) $; \mathrm{R}=$ Reverse (kebalikan); Q = Questionable (diragukan); I = Indifferent (biasa saja)

Tahap selanjutnya memproses hasil jawaban kuisioner dengan menggunakan tabulasi survei. Klasifikasi kategori dilakukan berdasarkan Blauth's formula (Berger, 1993), yaitu (1) jika (onedimensional + attractive + must be $)>($ indifferent + reverse + questionable) maka kategori diambil data maksimum dari (one-dimensional, attractive, mustbe), (2) jika (one-dimensional + attractive + must be $)<$ (indifferent + reverse + questionable $)$ maka kategori diambil data maksimum dari (indifferent, reverse, questionable), dan 3 ) jika (one-dimensional + attractive + must be $)=($ indifferent + reverse + questionable) maka kategori diambil data maksimum dari (one-dimensional, attractive, mustbe, indifferent, reverse, questionable).

Langkah terakhir adalah melakukan perhitungan tingkat kepuasan (IBT) dan ketidakpuasan (IWT). Menurut Mazler dan Hinterhuber (1998), koefisien tingkat kepuasan berkisar antara 0 sampai 1 , semakin mendekati 1 maka semakin mempengaruhi kepuasan konsumen dan tidak begitu mempengaruhi konsumen jika nilainya mendekati 0 . Untuk tingkat ketidakpuasan mendekati angka -1 maka ketidakpuasan konsumen semakin kuat apabila atribut tidak terpenuhi dan sebaliknya jika nilainya mendekati 0 maka tidak mempengaruhi ketidakpuasan konsumen. Berikut adalah cara menghitung nilai IBT dan nilai IWT:

$$
\begin{aligned}
\mathrm{IBT} & =\frac{\mathrm{A}+\mathrm{O}}{\mathrm{A}+\mathrm{O}+\mathrm{M}+\mathrm{I}} \\
\mathrm{IWT} & =-\frac{\mathrm{M}+\mathrm{O}}{\mathrm{A}+\mathrm{O}+\mathrm{M}+\mathrm{I}}
\end{aligned}
$$

Keterangan:

$\begin{array}{ll}\text { IBT } & =\text { if better than (tingkat kepuasan) } \\ \mathrm{IWT} & =\text { if worse than (tingkat kekecewaan) } \\ \mathrm{A} & =\text { Attractive (menarik) } \\ \mathrm{M} & =\text { Must-be (harus ada) } \\ \mathrm{O} & =\text { One-dimensional (satu dimensi) } \\ \mathrm{R} & =\text { Reverse (kebalikan) } \\ \mathrm{Q} & =\text { Questionable (diragukan) } \\ \mathrm{I} & =\text { Indifferent (biasa saja) }\end{array}$

\section{Analisis Prioritas Pengembangan Atribut "Beras Analog"}

Pengumpulan data dilakukan menggunakan metode survei dengan kuesioner dalam bentuk pertanyaan tertutup. Survei dilakukan kepada responden yang sama dengan tahap sebelumnya. Kuesioner yang diberikan kepada responden adalah kuesioner tingkat kepentingan atribut serta kuesioner penilaian terhadap produk beras "analog" dan beras (Sauerwein et al., 1996; Matzler dan Hinterhuber, 1998; Hsu, 2007; Chaudha, 2011). Data dianalisis dengan menghitung nilai Quality Improve Index (QI) untuk mengetahui prioritas pengembangan atribut beras "analog". Dimana menurut Sauerwein et al. (1996), strategi yang didapatkan dari metode Kano adalah memenuhi semua persyaratan must-be, menjadi kompetitif dengan persyaratan onedimensional, dan menonjol dari yang lain dengan persyaratan attractive. Namun dalam pengembangan produk tidak berguna untuk berinvestasi dalam meningkatkan persyaratan must-be yang sudah berada pada tingkat yang memuaskan tetapi lebih baik untuk meningkatkan persyaratan onedimensional atau attractive karena berpengaruh besar terhadap kualitas produk yang dirasakan dan berakibat kepada tingkat kepuasan pelanggan.

Langkah awal yang dilakukan dalam analisis adalah menghitung nilai traditional Improvement Ratio (IR) (Sauerwein et al., 1996; Matzler dan Hinterhuber, 1998; Hsu, 2007; Chaudha, 2011) dari atribut beras "analog" yang masuk ke dalam kategori must-be, one-dimensional, dan attractive yang didapatkan dari hasil pengisian kuesioner tingat kepentingan atribut dan kuesioner penilaian terhadap beras "analog" dan beras, dengan cara membagi target kepuasan dengan tingkat kepuasan produk saat ini.

$$
\mathrm{IR}=\frac{\text { Target }}{\text { Tingkat kepuasan produk saat ini }}
$$

Kemudian menghitung nilai Adjusted Improvement Ratio (AIR) (Sauerwein et al., 1996, Matzler dan Hinterhuber, 1998; Hsu, 2007; Chaudha, 2011) yang dapat dihitung dengan rumus sebagai berikut:

$$
\mathrm{AIR}=I R^{\frac{1}{k}}
$$

Keterangan: AIR = Adjusted Improvement Ratio; IR $=$ Improvement Ratio $; \mathrm{k}=$ nilai $\mathrm{k}(\mathrm{k}=0,50$ untuk $\mathrm{M}$; $\mathrm{k}=1,00$ untuk $\mathrm{O}$; dan $\mathrm{k}=2,00$ untuk $\mathrm{A}$ )

Langkah terakhir adalah menghitung nilai Quality Improvement Index (QI). QI merupakan rasio perkalian antara kepentingan relatif dengan persyaratan produk yang merupakan selisih nilai 
antara produk sendiri dengan produk pesaing (Mazler dan Hinterhuber, 1998).

$$
\begin{gathered}
\mathrm{QI}=\text { kepentingan relatif } \mathrm{x} \text { (nilai produk sendiri - } \\
\text { nilai produk pesaing) }
\end{gathered}
$$

Nilai QI penting untuk strategi pengembangan produk dan dalam menentukan langkah-langkah perbaikan. Nilai ini merupakan indikasi betapa pentingnya persyaratan produk dalam hal persaingan. Semakin tinggi nilai pada kisaran positif, maka semakin tinggi keunggulan kompetitif relatif dalam kualitas produk yang dirasakan dari sudut pandang pelanggan. Namun, semakin tinggi nilai negatif dari indeks ini, maka semakin tinggi relatif disadvantage kompetitif. Oleh karena itu jauh lebih penting untuk meningkatkan persyaratan produk ini (Sauerwien et al., 1996).

\section{HASIL DAN PEMBAHASAN}

\section{Atribut yang menjadi Pertimbangan dalam Membeli Beras}

Survei dilakukan untuk mengetahui atribut yang menjadi pertimbangan dalam melakukan pembelian beras. Survei dilakukan dalam bentuk wawancara terbuka terhadap 30 responden yang merupakan konsumen "beras analog" dan segmentasi pasarnya. Data yang didapatkan dari wawancara dicatat dan kemudian dilakukan pengelompokkan atribut. Adapun hasil analisis distribusi frekuensi atribut yang dihasilkan dari waancara terhadap responden dapat dilihat pada Tabel 2.

Tabel 2 menunjukkan bahwa dari hasil wawancara terhadap konsumen "beras analog" terdapat 10 atribut yang menjadi pertimbangan dalam membeli beras (voice of customer) yang meliputi rasa yang enak, tekstur yang pulen, tinggi serat, IG rendah, beragam jenis dan rasa, aroma yang wangi, ketahanan produk setelah dimasak, mudah diperoleh, harga yang ekonomis, dan mudah dimasak. Menurut segementasi pasar "beras analog" terdapat 14 atribut yang menjadi pertimbangan dalam membeli beras (voice of customer) yang meliputi rasa yang enak, tekstur yang pulen, IG rendah, tinggi kalori, aroma yang wangi, ketahanan produk setelah dimasak, mudah diperoleh, harga yang ekonomis, kemasan yang kuat melindungi produknya, kemasan yang dapat memperlihatkan produknya, bersih, warna yang putih, ukuran butiran yang besar, dan bentuk butiran yang utuh.

Jika dilihat dari Tabel 2 terdapat perbedaan pertimbangan dalam membeli beras antara responden yang merupakan konsumen "beras analog" dan responden yang merupakan segmentasi pasar "beras analog", hal tersebut dikarenakan konsumen "beras analog" sudah mempertimbangkan atribut manfaat atau kandungan dari sumber pangan pokok yang dikonsumsi, sedangkan segmentasi pasar "beras analog" belum mempertimbangkan atribut tersebut dan lebih mempertimbangkan atribut sensori dari sumber pangan pokok yang dikonsumsi.

\begin{tabular}{|c|c|c|c|c|}
\hline \multirow[b]{2}{*}{$\begin{array}{c}\text { Kode } \\
\text { Atribut }\end{array}$} & \multirow[b]{2}{*}{ Atribut } & \multicolumn{3}{|c|}{ Frekuensi atribut berdasarkan tipe responden } \\
\hline & & Konsumen & $\begin{array}{l}\text { Segmentasi } \\
\text { pasar }\end{array}$ & $\begin{array}{l}\text { Konsumen dan } \\
\text { segmentasi pasar }\end{array}$ \\
\hline A1 & Rasa yang enak & 3 & 14 & 17 \\
\hline $\mathrm{A} 2$ & Tekstur yang pulen & 4 & 17 & 21 \\
\hline A3 & Tinggi serat & 3 & 0 & 3 \\
\hline A4 & IG rendah & 3 & 2 & 5 \\
\hline A5 & Tinggi kalori & 0 & 1 & 1 \\
\hline A6 & Beragam jenis dan rasa & 1 & 0 & 1 \\
\hline A7 & Aroma yang wangi & 3 & 16 & 19 \\
\hline A8 & $\begin{array}{l}\text { Tahan lama dalam waktu sehari setelah } \\
\text { dimasak }\end{array}$ & 1 & 1 & 2 \\
\hline A9 & Mudah diperoleh & 1 & 4 & 5 \\
\hline A10 & Harga yang ekonomis & 1 & 9 & 10 \\
\hline A11 & Mudah dimasak & 1 & 0 & 1 \\
\hline A12 & Kemasan yang kuat melindungi produknya & 0 & 1 & 1 \\
\hline A13 & $\begin{array}{l}\text { Kemasan yang dapat memperlihatkan } \\
\text { produknya }\end{array}$ & 0 & 1 & 1 \\
\hline A14 & Bersih & 0 & 10 & 10 \\
\hline A15 & Warna yang putih & 0 & 6 & 6 \\
\hline A16 & Ukuran butiran yang besar & 0 & 2 & 2 \\
\hline A17 & Bentuk butiran yang utuh & 0 & 1 & 1 \\
\hline
\end{tabular}

Tabel 2. Atribut yang menjadi pertimbangan responden dalam membeli beras 
Jika dilihat dari gabungan konsumen dan segmentasi pasar "beras analog" maka terdapat 17 atribut yang menjadi pertimbangan dalam melakukan pembelian beras (voice of customer) yang terdiri dari atribut penilaian mutu organoleptik (rasa yang enak, tekstur yang pulen, beragam jenis dan rasa, aroma yang wangi, warna yang putih, ukuran butiran yang besar, serta bentuk butiran yang utuh), kandungan gizi (tinggi serat, IG rendah, dan tinggi kalori), kemudahan (kemudahan memperoleh dan kemudahan dimasak), harga (harga yang ekonomis), kemasan (kemasan yang kuat dan kemasan yang memperlihatkan produknya), ketahanan (konsistensi produk setelah dimasak), dan kebersihan (bersih dan tidak terdapat pengotor).

Tabel 2 menunjukkan bahwa atribut yang menjadi pertimbangan terbanyak responden dalam membeli beras jika dilihat dari frekuensinya dan menempati peringkat satu sampe lima adalah (1) atribut tekstur yang pulen; (2) atribut aroma yang wangi; (3) atribut rasa yang enak; (4) atribut harga yang ekonomis dan atribut kebersihan; serta (5) atribut warna yang putih. Jika dilihat dari keenam atribut tersebut maka dapat dilihat bahwa empat atribut dari enam atribut merupakan atribut yang tergolong dalam penilaian mutu organoleptik beras. Hal tersebut membuktikan bahwa mutu organoleptik sangat mempengaruhi penerimaan dan daya tarik beras bagi responden, sehingga menjadikan pertimbangan utama responden dalam melakukan pembelian beras. Menurut Singham et al. (2015) sifat sensori dari produk merupakan atribut yang penting, karena atribut tersebut yang paling sering menjadi perhatian utama oleh konsumen dan karena menentukan dapat diterima atau tidaknya produk oleh konsumen.

\section{Tingkat Kepuasan dan Ketidakpuasan Atribut Beras "Analog"}

Survei dilakukan untuk mengetahui kepuasan dan ketidakpuasan atribut "beras analog" jika dilihat dari 17 atribut yang menjadai pertimbangan dalam membeli beras. Survei dilakukan melalui pengisian kuesioner tertutup. Kuesioner yang digunakan adalah kuesioner Kano yang berisi pertanyaan functional dan dysfunctional. Pengisian kuesioner dilakukan oleh 30 responden yang merupakan responden yang sama dengan penelitian pada tahap sebelumnya. Hasil yang didapatkan dari pengisian kuesioner dianalisis menggunakan metode Kano untuk mengetahui klasifikasi kategori atribut dan untuk mengetahui atribut yang menyebabkan kepuasan yang dapat dilihat melalui nilai if better than (IBT) dan if worse than (IWT) yang dihasilkan. Adapun hasil analisis dapat dilihat pada Tabel 3.

Hasil analisis klasifikasi yang dihasilkan pada Tabel 3 terkait atribut yang berpengaruh terhadap kepuasan dan ketidakpuasan responden jika atribut tersebut terdapat pada produk beras "analog", bahwa:
1. Terdapat satu atribut yang masuk ke dalam klasifikasi kategori must-be (harus ada) yaitu atribut A1 (rasa yang enak), sehingga dapat dikatakan bahwa ketika atribut must-be tidak terpenuhi maka responden akan merasa tidak puas (Wang dan Ji, 2010).

2. Terdapat enam atribut yang masuk ke dalam klasifikasi kategori one-dimensional (satu dimensi) yaitu atribut A2, A3, A7, A8, A11, dan A14, sehingga dapat dikatakan bahwa kepuasan responden berkorelasi positif dengan pemenuhan atribut one-dimensional (Wang dan Ji, 2010).

3. Terdapat satu atribut yang masuk ke dalam klasifikasi kategori attractive (menarik) yaitu atribut A10 (harga yang ekonomis), sehingga dapat dikatakan bahwa kepuasan responden akan meningkat lebih besar jika attractive terpenuhi, sebaliknya jika atribut ini tidak terpenuhi tidak akan menyebabkan ketidakpuasan responden (Wang dan Ji, 2010).

4. Terdapat sembilan atribut yang masuk ke dalam klasifikasi kategori indifferent (biasa saja) yaitu atribut A4, A5, A6, A9, A12, A13, A15, A16, dan A17, sehingga dapat dikatakan bahwa responden akan mengabaikan atribut yang masuk ke dalam kategori indifferent (Wang dan $\mathrm{Ji}$, 2010).

Selanjutnya dari hasil klasifikasi kategori atribut yang dihasilkan dilakukan perhitungan nilai IBT dan IWT untuk mengetahui atribut yang menyebabkan kepuasan dan ketidakpuasan jika dimiliki oleh "beras analog". Hasil analisis yang dihasilkan dari analisis nilai IBT dan IWT pada Tabel 4 dapat dilihat bahwa:

1. Atribut yang memiliki nilai IBT yang mendekati 1 adalah atribut A7 (aroma yang wangi) dengan nilai 0,70 . Nilai tersebut menunjukkan bahwa kepuasan responden akan meningkat dengan pemenuhan kualitas atribut tersebut pada "beras analog" (Berger et al., 1993), sehingga atribut A7 penting terhadap kepuasan.

2. Atribut yang memiliki nilai IWT yang mendekati -1 adalah atribut A14 (bersih) dengan nilai -0,90. Nilai tersebut menunjukkan bahwa kepuasan responden akan menurun dengan tidak terpenuhinya kualitas atribut tersebut pada "beras analog" (Berger et al., 1993), sehingga atribut A14 penting terhadap kepuasan.

3. Atribut yang memiliki nilai IBT menjauhi 1 dengan nilai 0,14 dan memiliki nilai IWT menjauhi - 1 dengan nilai 0,04 adalah atribut A16 (ukuran butiran yang besar). Nilai tersebut menunjukkan bahwa pemenuhan atribut ini pada "beras analog" tidak akan berpengaruh terhadap kepuasan responden. Hal tersebut dikarenakan atribut ini cenderung diabaikan oleh responden, sehingga atribut A16 tidak penting terhadap kepuasan. 
Tabel 3. Nilai koefisien kepuasan dan ketidakpuasan

\begin{tabular}{|c|c|c|c|c|c|c|c|c|}
\hline \multirow{2}{*}{ Atribut } & \multicolumn{6}{|c|}{ Kategori } & \multirow{2}{*}{ Nilai IBT } & \multirow{2}{*}{ Nilai IWT } \\
\hline & $\mathbf{A}$ & $\mathbf{M}$ & $\mathbf{O}$ & $\mathbf{R}$ & $\mathbf{Q}$ & I & & \\
\hline$\overline{\mathrm{A} 1}$ & 6 & 11 & 6 & 0 & 0 & 7 & 0,40 & $-0,57$ \\
\hline A2 & 5 & 6 & 10 & 1 & 0 & 8 & 0,52 & $-0,55$ \\
\hline A3 & 7 & 1 & 10 & 0 & 4 & 8 & 0,65 & $-0,42$ \\
\hline A4 & 6 & 4 & 5 & 0 & 1 & 14 & 0,38 & $-0,31$ \\
\hline A5 & 4 & 5 & 3 & 5 & 0 & 13 & 0,28 & $-0,32$ \\
\hline A6 & 6 & 0 & 2 & 1 & 0 & 21 & 0,28 & $-0,07$ \\
\hline A7 & 5 & 2 & 16 & 0 & 0 & 7 & 0,70 & $-0,60$ \\
\hline A8 & 5 & 7 & 11 & 0 & 0 & 7 & 0,53 & $-0,60$ \\
\hline A9 & 8 & 6 & 0 & 0 & 0 & 16 & 0,27 & $-0,20$ \\
\hline A10 & 9 & 5 & 5 & 1 & 2 & 8 & 0,52 & $-0,37$ \\
\hline A11 & 3 & 8 & 14 & 0 & 0 & 5 & 0,57 & $-0,73$ \\
\hline A12 & 2 & 7 & 4 & 0 & 0 & 17 & 0,20 & $-0,37$ \\
\hline A13 & 4 & 5 & 6 & 0 & 0 & 15 & 0,33 & $-0,37$ \\
\hline A14 & 0 & 11 & 16 & 0 & 0 & 3 & 0,53 & $-0,90$ \\
\hline A15 & 4 & 1 & 3 & 1 & 0 & 21 & 0,24 & $-0,14$ \\
\hline A16 & 3 & 0 & 1 & 2 & 0 & 24 & 0,14 & $-0,04$ \\
\hline A17 & 5 & 0 & 7 & 0 & 0 & 18 & 0,40 & $-0,23$ \\
\hline
\end{tabular}

Keterangan: $\mathrm{A}=$ Attractive (menarik); $\mathrm{M}=$ Must-be (harus ada); $\mathrm{O}=$ One-dimensional (satu dimensi); $\mathrm{R}=$ Reverse (kebalikan); $\mathrm{Q}=$ Questionable (diragukan); I = Indifferent (biasa saja); IBT = if better than (tingkat kepuasan); IWT = if worse than (tingkat kekecewaan); atribut A1-A17 mengacu pada Tabel 2

\section{Prioritas Pengembangan Atribut Beras "Analog”} Survei dilakukan untuk mengetahui prioritas pengembangan atribut "beras analog" jika dilihat dari 17 atribut yang menjadi pertimbangan responden dalam membeli beras yang masuk ke dalam kategori must-be, one-dimensional, dan attractive. Survei dilakukan dalam bentuk pengisian kuesioner tertutup berupa kuesioner tingkat kepentingan atribut serta kuesioner penilaian terhadap produk "beras analog" dan beras. Survei dilakukan terhadap 30 responden yang merupakan responden yang sama dengan penelitian tahap sebelumnya. Hasil pengisian kuesioner dianalisis dengan menghitung nilai kepentingan relatif atribut "beras analog" dan prioritas pengembangan atribut "beras analog". Prioritas pengembangan atribut tersebut dilihat dari atribut yang memiliki nilai QI paling rendah.

Menurut Sauerwein et al. (1996), strategi yang didapatkan dari metode Kano adalah memenuhi semua persyaratan must-be, menjadi kompetitif dengan persyaratan one-dimensional, dan menonjol dari yang lain dengan persyaratan attractive yang mengacu pada hasil analisis yang didapatkan pada Tabel 3. Tabel 3 menunjukkan bahwa dari 17 atribut yang menjadi pertimbangan dalam membeli beras hanya terdapat delapan atribut yang perlu dilakukan pengembangan karena masuk ke dalam kategori must-be, one-dimensional, dan attractive. Delapan atribut tersebut meliputi atribut A1, A2, A3, A7, A8, A10, A11, dan A14. Sedangkan sembilan atribut lainnya yaitu atribut $\mathrm{A} 4$, A5, A6, A9, A12, A13, A15, A16, dan A17 merupakan atribut yang tergolong ke dalam indifferent sehingga tidak perlu dilakukan pengembangan terhadap sembilan atribut tersebut.
Hal tersebut dikarenakan responden cenderung mengabaikan atribut yang masuk ke dalam kategori indifferent (Wang dan Ji, 2010)

Adapun hasil tingkat kepentinga dan prioritas pengembangan delapan atribut beras "analog" dapat dilihat pada Tabel 4. Tabel 4 menunjukkan hasil pengisian kuesioner mengenai tingkat kepentingan atribut serta penilaian terhadap atribut yang dimiliki oleh beras "analog" dan beras. Dari data yang didapatkan kemudian dilakukan analisis untuk melihat nilai kepentingan relatif dari atribut beras "analog" dan prioritas pengembangan atribut beras "analog". Hasil analisis tingkat kepentingan yang didapatkan dari delapan atribut tersebut dari yang paling tinggi hingga paling rendah adalah atribut A1 dengan nilai kepentingan relatif sebesar 19,84; atribut A7 dengan nilai kepentingan relatif sebesar 12,98; atribut A10 dengan nilai kepentingan relatif sebesar 12,72; atribut A8 dengan nilai kepentingan relatif sebesar 11,82; atribut A14 dengan nilai kepentingan relatif sebesar 9,74; atribut A3 dengan nilai kepentingan relatif sebesar 9,52; dan atribut A11 dengan nilai kepentingan relatif sebesar 9,15.

Hasil analisis prioritas pengembangan atribut yang terdapat pada Tabel 4 menunjukkan bahwa terdapat lima atribut beras "analog" yang memiliki nilai QI negatif yaitu atribut A1 sebesar 25,80; atribut A10 sebesar -21,63; atribut A7 sebesar -20,76; atribut A2 sebesar -16,49; dan atribut A8 sebesar -7,92. Nilai QI yang dihasilkan tersebut penting untuk strategi pengembangan produk dan dalam menentukan langkah-langkah perbaikan, hal tersebut dikarenakan semakin tinggi nilai negatif dari nilai QI maka semakin tinggi relatif disadvantage kompetitifnya. 
Tabel 4. Tingkat kepentingan relatif dan prioritas pengembangan atribut

\begin{tabular}{|c|c|c|c|c|c|c|c|c|c|c|}
\hline \multirow[t]{2}{*}{$\mathbf{A}$} & \multirow[t]{2}{*}{ TK } & \multicolumn{2}{|c|}{$\begin{array}{c}\text { Analisis } \\
\text { persaingan }\end{array}$} & \multirow[t]{2}{*}{ Target } & \multirow[t]{2}{*}{ IR } & \multirow[t]{2}{*}{ Nilai K } & \multirow[t]{2}{*}{ AIR } & \multirow[t]{2}{*}{$\mathbf{A I}$} & \multirow[t]{2}{*}{$\mathbf{R I}$} & \multirow[t]{2}{*}{ QI } \\
\hline & & Sendiri & Pesaing & & & & & & & \\
\hline A1 & 4,37 & 2,90 & 4,20 & 4,20 & 1,45 & 0,50 & 2,10 & 9,17 & 19,84 & $-25,80$ \\
\hline $\mathrm{A} 2$ & 4,17 & 2,90 & 4,17 & 4,17 & 1,44 & 1,00 & 1,44 & 6,00 & 12,98 & $-16,49$ \\
\hline A3 & 4,40 & 4,13 & 3,07 & 4,13 & 1,00 & 1,00 & 1,00 & 4,40 & 9,52 & 10,09 \\
\hline A7 & 4,30 & 2,77 & 4,23 & 4,23 & 1,53 & 1,00 & 1,53 & 6,57 & 14,22 & $-20,76$ \\
\hline A8 & 4,50 & 3,13 & 3,80 & 3,80 & 1,21 & 1,00 & 1,21 & 5,46 & 11,82 & $-7,92$ \\
\hline A10 & 4,57 & 2,60 & 4,30 & 4,30 & 1,65 & 2,00 & 1,29 & 5,88 & 12,72 & $-21,63$ \\
\hline A11 & 4,23 & 4,23 & 4,03 & 4,23 & 1,00 & 1,00 & 1,00 & 4,23 & 9,15 & 1,83 \\
\hline A14 & 4,50 & 4,13 & 3,77 & 4,13 & 1,00 & 1,00 & 1,00 & 4,50 & 9,74 & 3,51 \\
\hline
\end{tabular}

Keterangan: $\mathrm{A}=$ atribut; $\mathrm{TK}=$ tingkat kepentingan; $\mathrm{K}=$ kategori; IR = improvement ratio; $\mathrm{AIR}=$ adjusted improvement ratio; $\mathrm{AI}=$ adjusted importance; $\mathrm{RI}=$ relative important; $\mathrm{QI}=$ quality improvement; atribut A1, A2, A3, A7, A8, A10, A11, dan A14 mengacu pada Tabel 3.

Oleh karena itu jauh lebih penting untuk meningkatkan atribut produk dengan nilai negatif QI yang tinggi (Sauerwien et al., 1996). Jika dilihat dari kelima atribut tersebut terdapat tiga atribut beras "analog" yang masuk ke dalam atribut penilaian mutu organoleptik yang meliputi rasa yang enak, aroma yang wangi, dan tekstur yang pulen. Menurut Singham et al. (2015), atribut sensori merupakan atribut penting untuk pengembangan produk, karena berkaitan dengan penerimaan konsumen. Selain mutu organoleptik masih terdapat dua atribut yang juga memerlukan perbaikan yaitu harga yang ekonomis dan ketahanan produk setelah dimasak. Hasil penelitian ini menunjukan bahwa saat ini keberadaan beras "analog" belum dapat disetarakan dengan beras, sehingga perlu dilakukan upaya pengembangan terhadap atribut beras "analog" untuk meningkatkan penerimaan.

\section{KESIMPULAN DAN SARAN}

\section{Kesimpulan}

Kesimpulan yang didapatkan dari penelitian ini adalah: (1) terdapat 17 atribut yang menjadi pertimbangan dalam melakukan pembelian beras, namun hanya enam atribut yang menjadi pertimbangan utama yaitu tekstur yang pulen, aroma yang wangi, rasa yang enak, harga yang ekonomis, bersih, dan warna yang putih; (2) atribut yang berpengaruh terhadap tingkat kepuasan beras "analog" adalah aroma yang wangi dan bersih (tidak terdapat pengotor), serta atribut yang tidak berpengaruh terhadap kepuasan adalah ukuran butiran yang besar; dan (3) pengembangan beras "analog" diprioritaskan pada atribut (a) rasa yang enak, (b) harga yang ekonomis, (c) aroma yang wangi/tidak apek, (d) tekstur yang pulen, dan (e) ketahanan setelah dimasak.

\section{Saran}

Penelitian ini memberikan gambaran bahwa terdapat permasalahan mengenai penerimaan sensori dari produk "beras analog" jagung yang kurang diminati terutama dari segi rasa, aroma, dan tekstur.
Oleh karena itu perlu dilakukan pengembangan terhadap produk "beras analog", salah satu potensi yang dapat dilakukan untuk mengatasi permasalahan terkait rasa, aroma, dan tekstur adalah dengan melakukan diversifikasi bahan baku, salah satu contoh bahan baku yang dapat digunakan dalam diversifikasi tersebut adalah dengan menggunakan singkong.

\section{UCAPAN TERIMA KASIH}

Terima kasih kepada Direktur Jenderal Pendidikan Tinggi, Kementerian Pendidikan dan Kebudayaan atas biaya penelitian melalui Penelitian Unggulan Strategis Nasional (Pusnas) Tahun Ajaran 2016 No. 428/IT3.11/PN/2016 dengan judul "Komersialisasi Beras Analog Fungsional dari Bahan Baku Lokal Sebagai Vehicle Diversifikasi Pangan" yang dilaksanakan oleh Prof. Dr. Ir. Slamet Budijanto, M.Agr (sebagai ketua peneliti) dan Dr. Ir. Aji Hermawan, MM (sebagai anggota peneliti).

\section{DAFTAR PUSTAKA}

Berger C, Blauth R, Boger D, Bolster C, Burchill G, DuMouchel W, Pouliot F, Richter R, Rubinoff A, Shen D, Timko M, Walden D. 1993. Kano's method for understanding customer-defined quality. JCQM. 2(4): 3-35.

Budijanto S dan Muaris HJ. 2013. 40 Resep Kreatif Olahan Beras Analog Pangan Alternatif Mirip Beras dari Non-padi. Jakarta (ID): Gramedia.

Budijanto S. 2014. Beras Analog sebagai Vehicle Penganekaragaman Pangan. Bogor: PT. IPB Press.

Caesarina I dan Estiasih T. 2016. Beras analog dari garut (Maranta arundinaceae): Kajian Pustaka. JPA. 4(2): 498-504.

Chaudha A, Jain R, Singh AR, Mishra PK. Integration of Kano's model into quality function deploymen (qfd). Int J Adv Manuf Technol. 53(2011): 689-698. DOI: 10.1007/s00170-010-2867-0. 
Fusch PI dan Ness LR. 2015. Are we there yet? Data saturation in qualitative research. The Qualitative Report. 20(9):1 408-1416.

Hsu CH, Chang TM, Wang SY, Lin PY. 2007. Integrating Kano's model into quality function deployment to facilitate decision analysis for service quality. Proceedings of the 8th WSEAS - Int Conference on Mathematic and Computers in Business and Economics. Vancouver, Canada. 19 -21 Juni 2007.

[Kementan] Kementerian Pertanian. 2012. Roadmap Diversifikasi Pangan 2011 - 2015. Jakarta (ID): Kementan.

[Kementan] Kementerian Pertanian. 2015. Statistik Konsumsi Pangan Tahun 2015. Jakarta (ID): Kementan.

Kotler P dan Keller KL. 2009. Manajemen Pemasaran. Jakarta(ID): Penerbit Erlangga.

Matzler K dan Hinterhuber HH. 1998. How to make product development project more successful by integrating Kano's model of customer satisfaction into quality function deployment. J Technovat. 18(1): 25-38.

Rini ES. 2013. Peran pengembangan produk dalam meningkatkan penjualan. J Ekon. 16(1): 3038.

Rizki DA, Munandar JM, dan Andrianto MS. 2013. Analisis persepsi konsumen dan strategi pemasaran beras analog (analog rice). $J$ Manajem Organis. 4(2): 144-162.

Rusmadi. 2016. Analisis strategi pemasaran bisnis modern. Jurnal Ilmiah Indonesia. 1(4):69-78.

Sauerwien E, Bailkom F, Matzler K, Hinterhuber HH. 1996. The Kano model: how to delight your customers. Int Working Seminar on Production Economics. Innsbruck, Austria. 19-23 Februari 1996.

Singham P, Birwal P, dan Yadav BK. 2015. Importance of objective and subjective measurement of food quality and their interrelationship. J Food Process Technol. 6(9): 17. Doi: $10.4172 / 2157-7110.1000488$.

Sulistiyowati W dan Astuti CC. 2016. Statistika Dasar. Sidoarjo (ID): Umsida Press.

Swastika N, Yanto T, dan Hartati. 2013. Performansi kualitas atribut beras organik dan tingkat kepuasan konsumen beras organik di Kabupaten Sragen. J Agrin. 17(2): 103-112.

Wang T dan Ji P. 2010. Understanding customer needs through quantitative analysis of Kano's model. IJQRM. 27(2): 173-184.

Yuktyanta HB. 1998. Pengembangan Produk Baru sebagai Alat Strategies untuk Meraih Keunggulan Pasar yang Bersaing. Jakarta (ID): Universitas Indonesia. 